\title{
SESSION 1: Colonic physiology
}

\section{Human Colonic Potassium Channel Expression and Function in Ulcerative Colitis}

Geoffrey I Sandle

Leeds Institute of Molecular Medicine, St James's University Hospital, Leeds, UK

Ulcerative colitis (UC) is a common inflammatory bowel disease that usually affects the rectum and distal (sigmoid and descending) colon, but may be more extensive and cause a pan-colitis. Detailed studies in the 1980s showed that healthy human distal colon was characterized by mainly electrogenic $\mathrm{Na}^{+}$absorption, a lumen-negative transmucosal electrical potential difference (PD) of $\sim 25 \mathrm{mV}$, predominantly passive (paracellular) $\mathrm{Cl}^{-}$absorption down the transmucosal potential gradient, minimal net $\mathrm{K}^{+}$secretion and net water absorption, resulting in normal formed stools [1-3]. By contrast, in inflamed distal colon in patients with active $U C$, there was loss of electrogenic $\mathrm{Na}^{+}$absorption and the lumen-negative PD was negligible or absent, resulting in loss of passive $\mathrm{Cl}^{-}$absorption, while net $\mathrm{K}^{+}$ secretion was increased, with zero water absorption or net water secretion, leading to liquid, bloody stools [1-3].

More recently, there has been expansion of our understanding about the molecular basis of these transport abnormalities and how they contribute to the pathogenesis of diarrhoea in UC. We now know there is decreased expression or down-regulation of apical $\mathrm{Na}^{+}$channels $(\mathrm{ENaC})$, basolateral $\mathrm{Na}^{+}, \mathrm{K}^{+}$ATPase, the apical $\mathrm{Cl}^{-}: \mathrm{HCO}_{3}{ }^{-}$exchanger, and isoform-1 of the $\mathrm{Na}^{+}: \mathrm{H}^{+}$exchanger [4-7]. However, the cellular basis of increased colonic $\mathrm{K}^{+}$secretion seen in some cases of active $\mathrm{UC}$ has been unclear and is one of the themes of this presentation.

Since human colon is normally a $\mathrm{K}^{+}$secretory epithelium [1], it seemed likely that $\mathrm{K}^{+}$channels were expressed in the luminal (apical) colonocyte membrane. Based on the assumption that these $\mathrm{K}^{+}$ channels might resemble the high conductance luminal $\mathrm{K}^{+}(\mathrm{BK})$ channels previously identified in rat colon [8], we used molecular and patch-clamp recording techniques to evaluate the distribution and characteristics of BK channels in normal colon, as well as BK channel expression in healthy patients and those with UC [9]. In normal colon, BK channel $\alpha$-subunit protein was immunolocalised to surface cells and upper crypt cells, whereas in UC, although BK channel $\alpha$-subunit protein expression was unchanged in surface cells, it extended along the entire crypt axis irrespective of whether the disease was active or quiescent. BK channel $\alpha$-subunit protein and mRNA expression (evaluated by western blotting and real-time PCR, respectively) were similar in normal ascending and sigmoid colon. Of the four possible $\beta$-subunits $\left(\beta_{1-4}\right)$, the $\beta_{1^{-}}$and $\beta_{3}$-subunits were dominant. Furthermore, voltage-dependent, $\mathrm{Ba}^{2+}$-inhibitable $\mathrm{K}^{+}$channels with a unitary conductance of $214 \mathrm{pS}$ were identified at low abundance in the apical membrane of surface cells around the openings of intact crypts isolated 
from normal sigmoid colon. It would therefore appear that the more extensive distribution of apical BK channels along the surface-crypt axis in UC leaves the colonic epithelium poised for enhanced $\mathrm{K}^{+}$ secretion, leading to increased faecal $\mathrm{K}^{+}$losses in patients with active disease, similar to that seen in patients with end-stage renal disease [10] and in the rat model of chronic dietary $\mathrm{K}^{+}$enrichment [GI Sandle, unpublished observations]. We further postulated that faecal $\mathrm{K}^{+}$losses in UC may be dependent not only on the wider distribution of BK channels along the crypts, but also on the overall level of BK channel activity, which would be enhanced in active (but not quiescent) UC by inflammatory mediators (e.g. prostaglandin $\mathrm{E}_{2}$ ) acting through increases in cytosolic cAMP and/or $\mathrm{Ca}^{2+}$ concentrations. This notion was supported by patch-clamp studies in surface colonocytes from rats fed a $\mathrm{K}^{+}$enriched diet, which showed that apical BK channels were activated when exogenous forskolin and IBMX (to increase cytosolic cAMP) were added to cell-attached patches, and when the catalytic subunit of protein kinase A was applied to the cytosolic face of excised inside-out patches [11].

The second theme of this presentation is the potential role of $\mathrm{Ca}^{2+}$-sensitive, intermediate-conductance $(\sim 23 \mathrm{pS}) \mathrm{K}^{+}\left(\mathrm{IK}_{\mathrm{Ca}}\right)$ channels in the pathogenesis of diarrhoea in UC. We were the first to identify and characterize these channels in the basolateral membrane of human colonic crypt cells $[12,13]$ and our recent work [14] suggests that their altered expression may contribute to impaired electrogenic $\mathrm{Na}^{+}$ absorption, which is the critical ion transport defect in active UC [1,3-5]. Thus, immunolocalisation showed basolateral $\mathrm{IK}_{\mathrm{Ca}}$ channel protein along the entire surface-crypt axis in normal colon. By contrast, markedly decreased or absent $\mathrm{IK}_{\mathrm{Ca}}$ channel protein expression was a constant feature in active $\mathrm{UC}$, although $\mathrm{IK}_{\mathrm{Ca}}$ channel expression was restored in patients with disease in clinical and histological remission. This reduced $\mathrm{IK}_{\mathrm{Ca}}$ channel expression in active $\mathrm{UC}$ does not appear to be a nonspecific manifestation of mucosal inflammation, since normal patterns of $\mathrm{IK}_{\mathrm{Ca}}$ channel protein expression were seen in active Crohn's colitis, collagenous colitis and infective colitis. Despite the decrease in $\mathrm{IK}_{\mathrm{Ca}}$ channel protein expression in active UC, quantitative PCR using intact crypts (free of lamina propria inflammatory cells) isolated from colonoscopic biopsies did not reveal a significant difference in $\mathrm{IK}_{\mathrm{Ca}}$ channel RNA levels between 'control' patients without mucosal inflammation and patients with active $\mathrm{UC}$, suggesting a post-transcriptional defect in $\mathrm{IK}_{\mathrm{Ca}}$ channel synthesis in this disease. Patch-clamp studies in isolated crypts indicated that cell conductance was dominated by basolateral $\mathrm{IK}_{\mathrm{Ca}}$ channels in control patients. However, in patients with active UC (in whom immunostaining had indicated marked decreases in $\mathrm{IK}_{\mathrm{Ca}}$ channel protein expression), $\mathrm{IK}_{\mathrm{Ca}}$ channel abundance and overall activity were reduced by $53 \%(\mathrm{P}=0.03)$ and $61 \%(\mathrm{P}=0.04)$ respectively, which resulted in a $75 \%(\mathrm{P}=0.003)$ decrease in the estimated basolateral membrane $\mathrm{K}^{+}$conductance in UC patients compared with controls. Interestingly, in keeping with the restoration of normal levels of $\mathrm{IK}_{\mathrm{Ca}}$ channel protein expression in patients with quiescent $\mathrm{UC}, \mathrm{IK}_{\mathrm{Ca}}$ channel abundance and activity also returned to control values. 
The important question is, are the decreases in basolateral $\mathrm{IK}_{\mathrm{Ca}}$ channel abundance and activity likely to be important in the pathogenesis of impaired colonic $\mathrm{Na}^{+}$absorption in UC? If (in the absence of information about all relevant transport proteins and intracellular ion activities) we assume (i) apical and basolateral membranes are pure $\mathrm{Na}^{+}$and $\mathrm{K}^{+}$conductances, (ii) an apical/basolateral membrane resistance ratio of 2.3 [3], (iii) $\mathrm{E}_{\mathrm{Na}}^{+}$of $+55 \mathrm{mV}$ and $\mathrm{E}_{\mathrm{K}}^{+}$of $-90 \mathrm{mV}$, (iv) apical and basolateral membrane potentials are equal (i.e. commensurate with a low junctional resistance, as in UC), and (v) $\mathrm{Na}^{+}$pump activity is not rate limiting, then decreasing basolateral membrane $\mathrm{K}^{+}$conductance by $75 \%$ should decrease $\mathrm{Na}^{+}$current by $75 \%$ (quantitative agreement with the decrease in $\mathrm{K}^{+}$conductance is coincidental). In reality, the situation is more complex, given the decreases in $\mathrm{ENaC}$ expression and tight junctional resistance. Despite these reservations, this basic consideration of driving forces provides strong evidence that reduced basolateral $\mathrm{IK}_{\mathrm{Ca}}$ channel activity per se could have an appreciable effect on $\mathrm{Na}^{+}$absorption. It is therefore possible to propose a cellular model of electrogenic $\mathrm{Na}^{+}$transport in the distal colon and rectum of patients with active UC, in which decreased $\mathrm{IK}_{\mathrm{Ca}}$ activity results in cell depolarization, thereby diminishing the driving force for electrogenic $\mathrm{Na}^{+}$transport via the already-attenuated apical ENaC channels, leading to defective electrogenic $\mathrm{Na}^{+}$absorption (and as a consequence, impaired $\mathrm{Cl}^{-}$and water absorption) across the inflamed mucosa [14].

\section{References}

[1] Hawker PC, McKay JS, Turnberg LA. Gastroenterology 1980;79:508-511.

[2] Sandle GI, Hayslett JP, Binder HJ. Gut 1986;27:309-316.

[3] Sandle GI, Higgs N, Crowe P et al. Gastroenterology 1990;99:97-105.

[4] Greig ER, Boot-Handford RP, Mani V et al. J Pathol 2004;204:84-92.

[5] Amasheh S, Barmeyer C, Koch CS et al. Gastroenterology 2004;126:1711-1720.

[6] Yang H, Jiang W, Furth EE et al. Am J Physiol Gastointest Liver Physiol 1998;275:G1445-G1453.

[7] Khan I, Siddique I, Al-Awadi FM et al. Can J Gastroenterol 2003;17:31-36.

[8] Butterfield I, Warhurst G, Jones MN et al. J Physiol 1997;501.3:537-547.

[9] Sandle GI, Perry MD, Mathialahan T et al. J Pathol 2007;212:66-73.

[10] Mathialahan T, MacLennan KA, Sandle LN et al. J Pathol 2005;206:46-51.

[11] Perry MD and Sandle GI. Am J Physiol Gastointest Liver Physiol 2009;297:G159-G167.

[12] Sandle GI, McNicholas CM and Lomax RB. Lancet 1994;343:23-25.

[13] Bowley KA, Morton MJ, Hunter M et al. Gut 2003;52:854-860.

[14] Al-Hazza A, Linley JE, Aziz Q et al. J Pathol (in press). 


\title{
ATP-sensitive $\mathrm{K}^{+}$channels in rat colonic epithelium
}

\author{
Ervice Pouokam, Martin Diener
}

Institute for Veterinary Physiology and Biochemistry, Justus-Liebig-University Giessen, Germany

Introduction: ATP-sensitive $\mathrm{K}^{+}\left(\mathrm{K}_{\mathrm{ATP}}\right)$ channels have been found in several tissues including the heart, skeletal muscles, the kidney, the brain, smooth muscles, and cell types like the pancreatic $\beta$ cells. Their activity depends on intracellular nucleotides, especially ATP and MgADP which inhibit and stimulate the channel, respectively. Thus, they couple the metabolic stage of a given cell to its electrical activity, contributing thereby to crucial functions such as insulin secretion, regulation of blood pressure and cytoprotection. They are inwardly rectifying channels, which structurally appear as a hetero-octameric complex of two distinct types of protein subunits: a pore-forming subunit Kir6.x (Kir6.1 or Kir6.2) and a regulatory subunit that belongs to the sulfonylurea receptor (SUR) subfamily. Recently, we found they are involved in secretory mechanisms at rat colonic epithelium and we speculated they could be present on both basolateral and apical sides of the epithelium. But to date, nothing is known about rat distal colonic epithelial $\mathrm{K}_{\mathrm{ATP}}$ channels structure, constitution, localization, electrophysiological and pharmacological features.

The aim of this study was to characterize, identify and localize the $\mathrm{K}_{\text {ATP }}$ channels in the rat colonic epithelium.

Methods: Changes in short-circuit current $\left(\mathrm{I}_{\mathrm{sc}}\right)$ induced by the $\mathrm{K}_{\mathrm{ATP}}$ channel opener pinacidil $\left(5 \cdot 10^{-4}\right.$ $\mathrm{mol} \cdot \mathrm{l}^{-1}$ ) were measured in Ussing chambers and challenged by specific blockers. The channel subunits were identified and localized by immunohistochemistry and their identification was confirmed by RTPCR.

Results: A reproducible response to repetitive administration of pinacidil at each side of the epithelium was observed showing the drug did not induce a desensitization. However, opposite responses were observed depending on the site of administration: an increase in the $\mathrm{I}_{\mathrm{sc}}$ when applied at the serosal side and a decrease when applied at the mucosal side. At the serosal side, the response to pinacidil was significantly reduced in the serosal presence of the $\mathrm{K}_{\mathrm{ATP}}$ channel blockers glibenclamide $\left(5 \cdot 10^{-4} \mathrm{~mol} \cdot \mathrm{l}^{-1}\right)$ and gliclazide $\left(10^{-6} \mathrm{~mol} \cdot \mathrm{l}^{-1}\right)$, but not in presence of tolbutamide $\left(10^{-2} \mathrm{~mol} \cdot \mathrm{l}^{-1}\right)$. In contrast, at the mucosal side, none of these blockers was significantly effective. Immunoreactivities were detected for the $\mathrm{K}_{\mathrm{ATP}}$ channel subunits Kir6.1, Kir6.2, SUR1 and SUR2B, and appeared localized to both the basolateral and the apical membranes. The staining for SUR2A still has to be run. Their expression was confirmed by RT-PCR.

Conclusion: $\mathrm{K}_{\text {ATP }}$ channels with different pharmacological features are present on both the basolateral and the apical sides of the epithelium and are likely at least of three types: Kir6.1/SUR2B, Kir6.2/SUR1 and Kir6.2/SUR2B. 


\title{
Increased responsiveness of distal and proximal colon to carbachol at the beginning of colitis development in mouse
}

\author{
Miroslav Hock ${ }^{1,2}$, Matúš Soták ${ }^{1}$ and Jiř́i Pácha ${ }^{1,2}$ \\ ${ }^{I}$ Institute of Physiology, Academy of Sciences of the Czech Republic, Prague, Czech Republic \\ ${ }^{2}$ Department of Physiology, Faculty of Science, Charles University, Prague, Czech Republic
}

Introduction: Close relationship between $\mathrm{Cl}^{-}$secretion and stool water content in colon is almost generally accepted. Accordingly, described decrease of inflamed distal colon responsiveness to carbachol and other secretagogues seems to be contradictory to watery stool observed in different models of colitis.

The aim of the study was to elucidate responsiveness of distal and proximal colon to carbachol during colitis development, that is before the observed decline of responsiveness, and to describe changes of carbachol-induced current in inflamed proximal colon.

Methods: We used Balb/c mice 10-14 weeks old and whole thickness segments of distal and proximal colon were placed to Ussing chambers. Experimental colitis was induced by 7 days administration of $2 \%$ dextran sodium sulfate (DSS). Responses to carbachol were measured as short-circuit current (SCC) on the $3^{\text {rd }}$, the $5^{\text {th }}$ and $7^{\text {th }}$ day of colitis development.

Results: Unexpectedly after 3 days of DSS administration responsiveness to carbachol significantly increased in distal and also in proximal colon compared to untreated mice. Responses to carbachol were measured in the presence of $\mathrm{Ba}^{2+}$ applied to mucosal side to inhibit $\mathrm{K}^{+}$secretion, a negative component of total SCC. An important role of enteric nervous system and prostaglandins in this increase was demonstrated by tetrodotoxin and indomethacin addition. After 7 days of DSS administration carbachol-induced SCC was suppressed in distal colon compared to untreated mice, but remains unchanged in proximal colon.

We conclude that suppressed responsiveness to carbachol is restricted only to distal colon and that it is preceded by increased responsiveness observed on the $3^{\text {rd }}$ day of colitis development in both, distal and proximal colon.

The study was supported by grant from Charles University (GA UK 25410). 